\title{
Social worldviews and social attitudes: Examining the psychological correlates for other- concern
}

Tosin Tunrayo Olonisakin*1, Sulaiman Olanrewaju Adebayo² \& Erhabor Sunday Idemudia ${ }^{1}$

*Corresponding Author: tosinsakin@yahoo.com

1. Faculty of Humanities, North-West University, South Africa

2. Ekiti State University, Ado-Ekiti, Nigeria

Received : 2021-04-27

Revised : 2021-07-02

Accepted : 2021-07-03

10.46303/jcve.2021.7

\begin{abstract}
How to cite this paper: Olonisakin, T. T., Adebayo, S. O., \& Idemudia, E. S. (2021). Social worldviews and social attitudes: Examining the psychological correlates for other-concern. Journal of Culture and Values in Education, 4(2), 65-83. https://doi.org/10.46303/jcve.2021.7
\end{abstract}

This is an Open Access article distributed under the terms of the Creative Commons Attribution 4.0 International license (https://creativecommons.org/licenses/by/4.0/)

\begin{abstract}
Social inequality or inequity is existent in every society. As such, most societies dedicate efforts to ensuring fairness and justice for all their members. The university environment constitutes a miniature society on its own and everyday broader realities of the larger society are equally applicable within the university. The attitude that students hold with regards to social inequality could be a function of their worldviews which act as guiding principles for social conduct. In this study, the worldviews of self-transcendence and just-world beliefs were examined in relation to support for affirmative action and social dominance orientation among students. The study employed a survey approach with data collected through questionnaires from a sample of 331 (62.8\% female) undergraduate students in a public university. The authors hypothesized that self-transcendence and just-world beliefs would be positively associated with support for affirmative action and negatively with social dominance orientation. The result of data analysis using structural equation modelling confirmed the hypotheses in this study. However, the relationship between just-world beliefs and social dominance orientation was not significant. Results were discussed for their implications for the acceptance of social policies that try to bridge the gap between dominant and marginalised groups. The implication of findings for understanding and managing interaction between groups in an educational setting was emphasised. Recommendations were made regarding how policymakers can use knowledge of worldviews held by students in designing strategies geared towards acceptance of policies targeted at ensuring positive outcomes for members of disadvantaged groups. Suggestions for future research were given.
\end{abstract}

Keywords: worldviews, social attitude, self-transcendence, just-world belief, affirmative action, social dominance orientation 
Olonisakin, T. T. et al., Social worldviews and social attitudes:

Examining the psychological correlates for other-concern

\section{Introduction}

The university environment is a microcosm in which the social realities of the larger society are played out. The prevailing social issues that are observed in the larger society equally exist within the university community. Competition, social inequality, equity, fairness, and justice are topical issues in the university system. For instance, course grading system, financial aid services, course workload, socio-economic status, admission quotas, ethnic diversity and inclusion, and space allocation are realities within the university system that could make salient, issues of inequality or inequity and other social differences variables.

Within the university setup, inequity or inequality issues arise concerning group diversity, the equitable treatment of all social and natural groups, and the accommodation of the peculiar needs of certain groups. As such, policies are sometimes put in place to ensure the social inclusion of disadvantaged groups. Such special considerations for some categories of people are sometimes met with resistance due to the ideologies that people hold towards such types of preferential treatments. Two prominent social attitudes on inequality that are particularly relevant to the university domain are attitudes towards affirmative action and social dominance orientation.

Affirmative action (AFF) refers to actions, policies, programs, laws, and structures geared towards ensuring that all peoples have equal opportunity to resources regardless of their social categorisations. They are intended to improve outcomes for underrepresented, marginalised, or disadvantaged minority groups. AFF in education encompasses policies and laws that have been put in place to ensure that people of all races or ethnic categories and other social categories are given equal opportunity or access to education. This could be in the form of financial services and outreach programmes for indigent minority students and admission quotas to ensure that all groups have the opportunity for consideration. Another parallel goal of AFF beyond equal opportunities for all is ensuring diversity (Ashanti, 2008; Crosby et al., 2006; Morgenroth \& Ryan, 2018) and promoting peaceful relations between groups. This idea is borne out of literature that has established that contact between groups can help to improve tolerance and relations between them (Bandyopadhyay \& Green, 2018; Scacco \& Warren, 2018; Verkuyten et al., 2019). An opposition to AFF means detesting policies, laws, and processes that favour people of minority status or marginalised groups. This could also extend to discriminatory attitudes towards beneficiaries of AFF (Ashanti, 2008).

Social dominance orientation (SDO) is another social attitude that bothers on social inequality or hierarchical ordering of groups. The concept of SDO was introduced as the central variable in social dominance theory proposed by Pratto et al. (1994). The authors linked this variable to the universal nature of inequality among social groups and the social processes that legitimise it. The authors proposed that SDO explains why people would be receptive to or unwelcoming of inequality-promoting ways of life between and among social groups. SDO motivates discriminatory attitudes towards individuals or groups that are considered as different, strangers, minority, or inferior (Kleppest $\varnothing$ et al., 2019; Mebane et al., 2020; Nilsson \& Jost, 2020). With a SDO an individual shows a penchant for ideas and policies that widen inequality or enhance hierarchy. Furthermore, such an individual may take on social roles that perpetuate or increase social inequality, be generally prejudiced, and categorise social groups along superiority-inferiority dimensions (Pratto et al., 1994). In addition, a SDO drives an individual to 
adopt hierarchy-legitimising myths, beliefs, values, and ideas that have achieved consensus as fair, moral, or natural (Jost \& Hunyady, 2005; Pratto et al., 1994; Pratto et al., 2006). For example, religious and genetic theories which appeal to the moral and intellectual justification of group-based inequality (Pratto et al., 1994; Pratto et al., 2006)

Social attitudes that favour discrimination and the outcomes they facilitate are the channels through which inequalities are maintained in societies. Such attitudes are likely to lead to the support of policies, processes, structures, and institutions that help to institutionalise and perpetuate oppression and discrimination (Olonisakin \& Adebayo, 2021; Pratto et al., 2006). In an environment that requires cooperation, healthy competition, tolerance, and trust such as a university environment, these attitudes are likely to produce negative outcomes in social interaction. Students from minority groups, international students, and students from other disadvantaged groups may find learning an unpleasant experience when they perceive discrimination in their learning environment. For instance, studies have shown that students who perceive discrimination from other students and systemic factors are likely to experience negative outcomes (Caplan \& Stevens, 2017; Mahsa, 2020; Dzansi \& Mogashoa, 2013; Ratshilaya, 2017). For example, Caplan and Stevens (2017) found among a sample of international students that perceived intolerance and lack of support from faculty members and domestic students affect the integration of international students. Similarly, Ratshilaya (2017) found discrimination and a lack of socialisation with domestic students as some of the factors responsible for acculturative challenges among international students.

On the contrary, studies have recorded the positive effect that a supportive and friendly learning environment can have for students particularly students of minority or disadvantaged groups. For instance, Dzansi and Mogashoa (2013) found that mindfulness about how classroom practices such as assessment, communication, teaching, and classroom organisation affect international students, helped to improve their learning experience. Likewise, Bai (2016) found social support from the university to be strongly associated with less acculturative stress among international students in the US. Furthermore, Akhtari et al. (2020) using administrative data from Texas, USA found that when AFF is in play, racial gaps between Whites and minorities in grade, SAT scores, attendance, and college applications reduce. Similarly, KPMG (2016) found that the Right to Education Act in India, an AFF put in place to provide free and compulsory education for indigent children led to a marked increase in enrolment of children in schools and a decrease in the dropout rate. Also, Dhakal (2017) using data from Indian found that AFF which supports the inclusion of minority groups (Scheduled Caste and Scheduled Tribe) in state legislative assemblies was associated with increased commitment of resources to education, increased enrolment of children in school, and reduced rate of dropout at all levels of education among this minority group. Koea et al. (2021) through a narrative review approach using 45 studies found that AFF programmes in the US directed at the inclusion of ethnic minorities and Indigenous peoples into selective specialist medical and surgical training programmes have effectively led to an increase in the number of ethnic minority medical school graduates.

These research findings suggest that with systemic support, the educational opportunities that were previously unavailable and aspirations that were previously inconceivable are made possible for members of minority or disadvantaged groups. Given the importance of a positive learning environment for students' successful learning outcomes, it is important to explore factors that may be responsible for discriminatory social attitudes. Such knowledge would 
illuminate the understanding of students' attitudes towards social inequality, unfavourable perception of minority students, and generally, social relations and conflicts among racial/ethnic groups.

Scholars have suggested that beyond viewing discrimination against outgroups as simply negative, there ought to be an investigation of the beliefs that underscore such attitudes (Glaser, 2005; Verkuyten et al., 2019). This is because ideological attitudes that favour inequity or inequality could be outcrops of deeply held perceptions or convictions of how the social world is ordered (Glaser, 2005; Verkuyten et al., 2019). Such perceptions about how the world, people, or events are structured or designed have been referred to as worldviews.

Worldviews refer to an individual's belief or perception about how the social world is organised or how it works. It is the perception of how things are in the world, what people are like, what can be expected of people, and how one ought to relate with others (Aerts et al., 2007; Barret, 2021). Worldviews are a collection of coherent concepts and theories with which people construct a holistic view of the world and an understanding of their varied experiences (Aerts et al., 2007; Barrett, 2021). They provide people with a template for coordinating and understanding different aspects of the world in terms of the relationship between people and the interconnectedness of events (Aerts et al., 2007; Flanagan, 2021). They serve as a motivating force that inspires, provides a sense of direction, and contributes to an individual's sense of self (Aerts et al., 2007; Flanagan, 2021).

How do people come about their worldviews? And what role do they play in an individual's behaviour? Worldviews develop through the process of socialisation and individual life experiences (Aerts et al., 2007; Flanagan, 2021). They are formed through direct experiences of the social world and the interpretations given to events that unfold around us (Aerts et al., 2007; Flanagan, 2021). Worldviews, thus serve as scripts and schema that guide people's actions and reactions to social stimuli.

Two prominent worldviews that have been largely investigated with regards to outgroup behaviour and social welfare are self-transcendence and just-world beliefs (Piedmont, 2012; Lucas et al., 2011; Yaden et al., 2017). The worldviews of self-transcendence and just-world belief are of interest in this study because it is the perception of the authors that they have underlying similarities. This is so in that both worldviews assume a universal order that directs life events and the recognition that human actions are the channels through which life events are produced (FeldmanHall et al., 2018; Stroebe et al., 2015). As such, they are worldviews that prescribe consciousness of the consequences of one's actions on others.

\section{Self-Transcendence (ST)}

Humans are constantly engaged with existential questions of what purpose their live serves and what links they have with happenings around them. Consequently, people try to construct meanings and purpose for their lives through adopting transcendent beliefs about their existence. ST is the belief that one's life has a broader meaning, purpose, and effect beyond immediate time and environment and a feeling of connectedness to nature and other beings (Piedmont, 2012). It is a belief that one's life is intricately linked to those of others which then influences the nature of the relationship held with people and the commitment made to such relationships. People high in ST hold the spiritual belief that life and events are beyond what is 
immediately perceivable to one and that one's actions have a broader effect on humankind (Piedmont, 2012).

To capture this phenomenon, Piedmont (1999) proposed the concept of spiritual transcendence which comprises three aspects of universality, interconnectedness, and prayer fulfilment. Universality represents a belief in the broadness of life and human existence. Interconnectedness captures a feeling of being connected to a larger reality that cuts across different groups and generations. Lastly, prayer fulfilment embodies feelings of joy and contentment from praying and enjoying a connection with a higher power. These dimensions of transcendence exemplify the experience of social reality as beyond the self. Transcendence beliefs influence the interpretation and meanings attached to events and the choices people make. The search for meaning and purpose in life is inbuilt in individuals, thus transcendence belief is universally held by people and constitutes a "fundamental inherent quality" of humans (Piedmont, 2012). As a driving force in humans, transcendence beliefs have thus been linked to pro-outgroup attitudes/concern for other's welfare. For example, Łowicki et al. (2020) found transcendence to be positively related to empathic concern. Likewise, Ardenghi et al. (2021) found ST to be positively associated with and predictive of emotional and cognitive aspects of empathy. Similarly, Pantaléon et al. (2019) found this variable to be directly related to selflessness. Also, Sugiura et al. (2020) reported ST to be linked to providing help to survivors of natural disasters.

\section{Just-World Belief (JWB)}

JWB is the human tendency to believe in a world where outcomes are consequences of one's actions and people deserve what they get (Lerner, 1980). This implies a world in which some level of controllability exists, where one can define and engineer outcomes for the self. This belief develops as an outcome of human existential needs to have a stable and predictable world in which one is not subject to random acts (Bierhoff, 2002; Lerner, 1980). Thus, JWB has been conceptualised as a worldview evoked to cope with life outcomes and has been linked to improvement in wellbeing and coping (Harding et al., 2020; Lucas et al., 2011; Khera et al., 2014). The belief in a just-world entails a belief in the fairness of procedures or of outcomes to which people are subjected (Lucas et al., 2011). It also takes the form of justice belief for the self and others (Lucas et al., 2011; Stroebe et al., 2015).

With regards to the relationship between JWB and social attitudes, research evidence links JWB with other-concern. For instance, Bègue et al. (2008) found that belief in a just-world for the self was associated with altruistic behaviour. Similarly, De Caroli and Sagone (2014) reported JWB to be associated with prosocial behaviour among adolescents. Likewise, Cheng et al. (2020) found JWB to be positively associated with employees' expression of ideas that could bring positive change to the organisation. The literature is however divided on how JWB relates to social attitudes with some linking JWB to less other-concern and harsh social attitudes. For example, it has been shown to reinforce preoccupation with self-interest among advantaged groups in the society (Wakslak et al., 2007), harsh social attitudes towards immigrants (Khera et al., 2014), negative attitudes towards people with mental illness (Bizer et al., 2012), and blaming of rape victims (Landström et al., 2015).

For the psychologist, the concern with worldviews is the understanding of their implications for social behaviour and relations. Specifically, how do they relate to values bothering on social 
inequality? ST and JWB have been established as having implications for social attitudes that border on equality or inequity and justice. Given the nature of these variables, it is hypothesised that ST and JWB would predict support for AFF and SDO. This is because a belief in a universal order or system and the unity of purpose invariably subsumes a belief that one's actions and inactions have a ripple effect and are implicated in the outcomes that other people get. As such, a belief in the interconnectedness of humankind should motivate a desire to improve life outcomes for other people. ST should therefore be associated with greater concern for the welfare of others and a commitment to social equity/equality. Likewise, JWB should motivate greater concern for the welfare of others and with mitigating social inequity/inequality. Thus the following hypotheses were tested in this study:

H1: ST would be positively associated with support for AFF and negatively associated with SDO.

H2: JWB would be positively associated with support for AFF and negatively associated with SDO.

While the authors recognise that some studies document an inverse relationship between JWB and other-concern (for example, Bizer et al., 2012; Khera et al., 2014; Landström et al., 2015), the authors are convinced that given the preceding discussion of what the worldview of JWB entails, the hypothesised relationship $(\mathrm{H} 2)$ ought to be obtained.

\section{Method}

\section{Participants}

To achieve a $90 \%$ power to detect at least a medium effect size of .15, the authors recruited 345 undergraduate students enrolled at a public university in Nigeria. Although sample size calculation using G*Power (Buchner et al., 2019) showed that a sample size of 88 is sufficient to achieve the a priori power and effects size, we overshot the minimum sample required to have enough data to explore the psychometric attributes of the measures to be utilised in this study. Due to reasons of univariate and multivariate outliers, 14 cases were excluded from analysis leaving a sample of 331.

Table 1: Demographic Characteristics of Participants

\begin{tabular}{lll}
\hline Variable & $\mathrm{N}$ & Percentage \\
\hline Sex & 123 & \\
Males & 208 & $37.2 \%$ \\
Females & & $62.8 \%$ \\
Ethnic Group & & \\
Yoruba & 291 & $87.9 \%$ \\
lgbo & 32 & $9.7 \%$ \\
Other & 8 & 2.4 \\
& & \\
Religion & & \\
Christians & 306 & $92.1 \%$ \\
Muslims & 25 & $7.9 \%$ \\
\hline
\end{tabular}


The average age of the participants was 21.57 (SD $=2.62$, range $=14-29)$, and $62.8 \%$ of participants were female. Participants were students in their second to fourth year and from the humanities disciplines. The ethnic groups reported were Yoruba $(291,87.9 \%)$, Igbo (32, $9.7 \%)$, and eight unspecified ethnic groups (2.4\%). Participants predominantly identified as Christians 92.1\% while others identified as Muslims (7.9\%).

\section{Measures}

Data on the study variables were collected through the use of standardised scales. Items from the different scales were pooled into a questionnaire with five sections addressing each of the variables.

\section{ST}

The first section contained items to measure ST. This variable was measured with the Universality dimension of the Spiritual Transcendence Scale by Piedmont (1999). Universality assesses a belief in the harmony and purposefulness of life (Piedmont, 2010). This dimension of transcendence was chosen because it captures the idea of transcendence emphasised in this study. That is, an individual's belief in the idea that there is a universal order to human existence and a universal plan in which people are connected and in which actions and inactions transcend the self. Nine items rated on a 5-point scale ranging from strongly disagree to strongly agree were used to assess the ST beliefs of participants. Higher scores indicate a higher belief in the transcendence of human existence. Sample items are "All life is interconnected" and "I feel that on a higher level all of us share a common bond". This scale has been widely used in psychological research and has been shown to have good psychometric properties (Simkin \& Piedmont, 2018). Piedmont (2010) reported a Cronbach's alpha of .86, Piedmont (2012) reported .82, Lau et al (2015) .67 and Piotrowski et al. (2019) .75.

\section{JWB}

JWB was measured with the Distributive Justice World Beliefs scale developed by Lucas et al. (2007) in the second section. This captures a belief that people deserve the outcomes or allocations they get (Lucas, 2009). The four items of this measure were rated on a 7-point scale ranging from 1 (strongly disagree) to 7 (strongly agree) with higher scores indicating a stronger belief about people getting the outcomes they deserve. Sample items are "Other people usually receive the outcomes that they deserve" and "Other people generally deserve the things that they are accorded". Previous research attests to the psychometric strength of the scale (Lucas et al., 2011). Lucas (2009) reported a Cronbach's alpha of .90 while Lucas et al. (2011) reported $.85, .87$, and .85 in three separate studies. The scale correlated positively with measures of harsh social attitude such as individual attitudes toward poverty and harsh attitudes toward individuals that have suffered economic hardship (Lucas et al., 2011).

\section{$A F F$}

The third section comprised items to measure support for AFF. The items were drawn from the AFF scale by Ashanti (2008). Seven items assessed the extent to which students are supportive of AFF in college and university admissions in the country. Items were modified to particularly suit the context of this study. For example, the statement "I believe the Supreme Court was wise to uphold affirmative action in college and university admissions" was modified 
as "I believe the laws of the country was wise to uphold affirmative action in college and university admissions". AFF's definition/description and specific examples were also provided to aid the students' understanding of the concept. The scale used a 7point rating scale ranging from 1 (strongly disagree) to 7 (strongly agree) with higher scores indicating higher support for AFF. Ashanti (2008) reported internal consistency of .98 as measured by Cronbach's alpha.

\section{$S D O$}

SDO was measured with four items from the eight-item Egalitarianism dimension of the SDO7 scale developed by Ho et al. (2017) in the fourth section. These items measure an individual's opposition to equality between groups. Only four items were selected for this study because prior studies (Olonisakin, 2019) found the remaining four items to demonstrate poor fit among student populations. Items were rated on a 7 point rating scale ranging from 1 (strongly disagree) to 7 (strongly agree) with higher scores indicating greater opposition to social equality. Sample items are "We should work to give all groups an equal chance to succeed" and "Group equality should be our ideal". All items are reverse-scored. Olonisakin (2019) reported a Cronbach's alpha of .84. This measure is positively associated with a tendency to justify the system (Olonisakin, 2019) and harsh social attitudes such as ingroup-centeredness and ingroup exclusivity (Olonisakin \& Adebayo, 2021).

\section{Demographic Data}

In addition to the preceding measures, participants were asked to report their sex, age, discipline, ethnic group, religion, and level of study in the last section of the questionnaire.

\section{Data Collection Technique}

Participants were invited through their course lecturers and assembled in a lecture hall. They were informed that the purpose of the research was to investigate social attitudes among university students. It was emphasised that their participation was voluntary and their responses will be kept confidential. The participants signed informed consent forms to indicate their voluntary participation in the study. The questionnaires were individually administered to all participants and they were implored to read the instructions carefully before responding.

\section{Result}

Data analyses were performed with SPSS version 20 and AMOS version 22. Pearson's correlation statistic was used to analyse the relationship between the variables of the study. Exploratory Factor Analysis (EFA) and Confirmatory Factor Analysis (CFA) was used to assess the factor structure and validity of the scales used for data collection. Structural Equation Modelling (SEM) was used to test the hypotheses in this study. With SEM, complex relationships between multiple variables can be modelled and tested simultaneously.

\section{Data Screening}

First, the data were screened for missing values. There were no missing values in the data set. Next, the data set was screened for univariate and multivariate outliers. For univariate outliers' identification, $z$-score $>/=3.29$ (Tabachnick \& Fidell, 1996) and values that exceed two or three standard deviations from the mean (Werner, 2003) criteria were used. For multivariate outlier identification, the Mahalanobis Distance was computed for each case. Cases with $p<.001$ were considered as multivariate outliers. Univariate and multivariate outlier identification led to the 
exclusion of 14 cases from the final analysis. Assumption of normality of data was verified with skewness and kurtosis. Kim (2013) recommends that a skewness value greater than two and a kurtosis value greater than seven would indicate "substantial non-normality" of the data set. Assumption of normality was fulfilled for the data set (see Table 2).

\section{Descriptive Statistics and Correlations among Study Variables}

The descriptive statistics and correlations among the study variables are displayed in Table 2 . ST was positively related to JWB $(r=.14, p=.011)$ and AFF $(r=.33, p<.01)$ and negatively with SDO $(r=-.30, p<.01)$. JWB was positively related to AFF $(r=.19, p<.01)$ and negatively with SDO $(r=-.14, p=.013)$. AFF was negatively related to SDO $(r=-.29, p<.01)$. Age and sex were not significantly related to any of the study variables.

Table 2: Means, Standard Deviations, and Correlations between Study Variables

\begin{tabular}{llllllllllll}
\hline & \multicolumn{1}{c}{$\mathrm{N}=331$} & & & & & & & & \\
Variables & 1 & 2 & 3 & 4 & 5 & 6 & $\mathrm{M}$ & SD & Skew & Kurt & $\alpha$ \\
\hline 1. ST & 1 & & & & & & 25.55 & 4.79 & -.22 & -.22 & .72 \\
2. JWB & $.14^{*}$ & 1 & & & & & 18.45 & 5.87 & -.39 & -.57 & .82 \\
3. AFF & $.33^{* *}$ & $.19 * *$ & 1 & & & & 15.41 & 4.05 & -.51 & -.09 & .68 \\
4.SDO & $-.30^{* *}$ & $-.14^{*}$ & $-.29 * *$ & 1 & & & 9.75 & 6.01 & .97 & .09 & .81 \\
5.Age & -.04 & -.08 & .07 & .09 & 1 & & 21.57 & 2.62 & & & \\
6.Sex & .03 & -.04 & -.03 & .06 & - & - & & & & & \\
\hline
\end{tabular}

Note: ST: Self-transcendence. JWB: just-world belief. AFF: affirmative action. SDO: social dominance orientation. Sex: male (1), female (2). Skew: skewness. Kurt: kurtosis.

$* p<.05$

$* * p<.01$.

\section{Measurement Model}

In order to ascertain the structure and validity of research instruments, an EFA and CFA were conducted to test a measurement model. First, an EFA was conducted on the items of the scales in this study. All items from the four scales were expected to load differently according to their respective latent construct. The maximum likelihood method with Oblimin rotation was selected with a specification to suppress item loadings less than .35. Analysis revealed that all items for the respective constructs loaded appropriately. Items 3 and 5 of the ST scale were dropped from the analysis. An examination of items 3 (I believe that on some level my life is intimately tied to all of humankind) and 5 (I believe that death is a doorway to another plane of existence) suggests that participants may have misunderstood the items or could not relate with them or found them ambiguous. Also, items 1, 2, 3, and 4 of the AFF scale were dropped from the analysis due to poor loadings. Upon examining these items, it showed that items 1 and 3 are contrait items. The tendency for contraits items to perform poorly in the setting of the study and particularly among the student population has been previously noted (Olonisakin, 2019). Examination of items 2 (All colleges and universities should have an affirmative action program) and 4 (It is reasonable for colleges and universities to give special consideration for admission to minorities) on the hand revealed that these two items may not have been relatable for the students for the following reasons. First, the AFF concerning education within the country is enforced through federal laws and regulations and not on an institutional basis. 
Second AFF is geared towards the representativeness of different states/ethnic groups rather than a specific focus on minority group considerations. Another EFA was run excluding the items with poor fit. The factor loadings for the ST scale ranged from .38 to.77; JWB .61 to .79, AFF .47 to .89 and SDO .58 to .86 . The internal consistency of the scales as measured by Cronbach's alpha was $.72, .82, .68$, and .81 respectively.

Next, a CFA was conducted on the measurement model. Items were entered into the model to load on their latent constructs. Kline (2005) recommends the use of four fit indices of Chisquare, $\mathrm{CFI}, \mathrm{RMSEA}$, and SRMR to determine model fit. The error terms between items 1 and 2 of JWB and between items 1 and 2 of SDO respectively were covaried to improve model fit. Analysis showed the model (figure 1) to have a relatively good fit as indicated by the following fit indices: $\chi^{2}=228.644, \mathrm{DF}=127, \chi^{2} / \mathrm{df}=1.80, p<.001, \mathrm{CFI}=.94, \mathrm{RMSEA}=.05,[90 \% \mathrm{Cl}=(.04, .06)]$, SRMR $=.06$. These fit indices meet the standards recommended in literature (Cangur \& Ercan, 2015; Hu \& Bentler, 1999; Kline, 2011). The measurement model is presented in Fig 1.

Figure 1: Measurement model

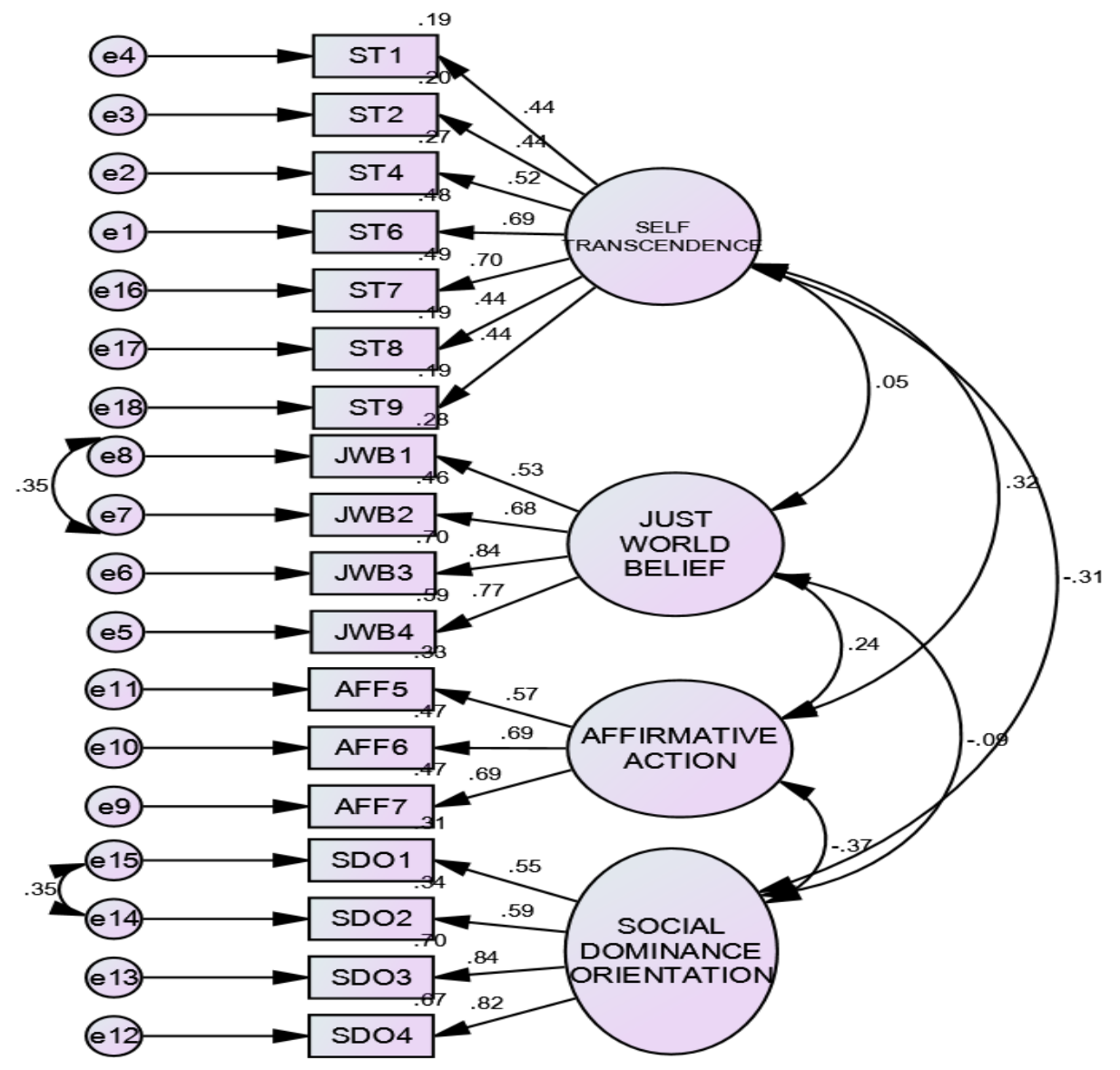

To test the hypotheses in this study a SEM was conducted. SEM using Maximum Likelihood Estimation was used in testing the predictive influence of the independent variables on the outcome variables. The combined measurement and structural model (figure 2 ) used in testing the study hypotheses achieved good fit; $\chi^{2}=242.547, \mathrm{DF}=128, \chi^{2} / \mathrm{df}=1.89, p<.001, \mathrm{CFI}=.93$, 
RMSEA $=.05,[90 \% \mathrm{Cl}=(.04, .06)]$, SRMR $=.06$. Results showing standardized regression weights (Table 3 ) indicated that ST positively predicted support for AFF $[\beta=.33, p<.001]$ and negatively predicted SDO $[\beta=-.33, p<.001]$ thus confirming hypothesis one. On the other hand, JWB positively predicted support for AFF $[\beta=.23, p=.002]$ but was not significant for SDO $[\beta=-.08, p=.202]$. Thus, hypothesis two was partly supported. ST and JWB predicted $16.6 \%$ [ $d$ $=.19]$ of the variance in support for AFF and $11.8 \%[d=.13]$ of the variance in SDO.

Furthermore, an invariance test was conducted to examine if the structural model would be influenced by sex. Analysis showed the structural model to be invariant across sex. Although the constrained model $\left[\chi^{2}=398.88, \mathrm{DF}=256, \chi^{2} / \mathrm{df}=1.56, p<.001, \mathrm{CFI}=.91, \mathrm{RMSEA}=.04,[90 \%\right.$ $\mathrm{Cl}=(.03, .05)] \mathrm{SRMR}=.08]$ achieved poor fit relative to to the unconstrained model, the chisquare difference was not significant. Furthermore, path by path analysis revealed no significant difference between males and females. Regardless of the invariance found, the analysis showed that ST predicted higher support for AFF among males $[\beta=.39, p=.005]$ relative to females $[\beta=.30, p=.002]$. Also, it predicted less SDO among females $[\beta=-.34, p$ $<.001$ ] relative to males [ $\beta=-.29, p=.02]$. JWB predicted higher support for AFF among males $[\beta=.24, p=.05]$ relative to females $[\beta=.19, p=.02]$.

Figure 2: Combined measurement and structural model: Path analysis from ST and JWB to AFF and SDO

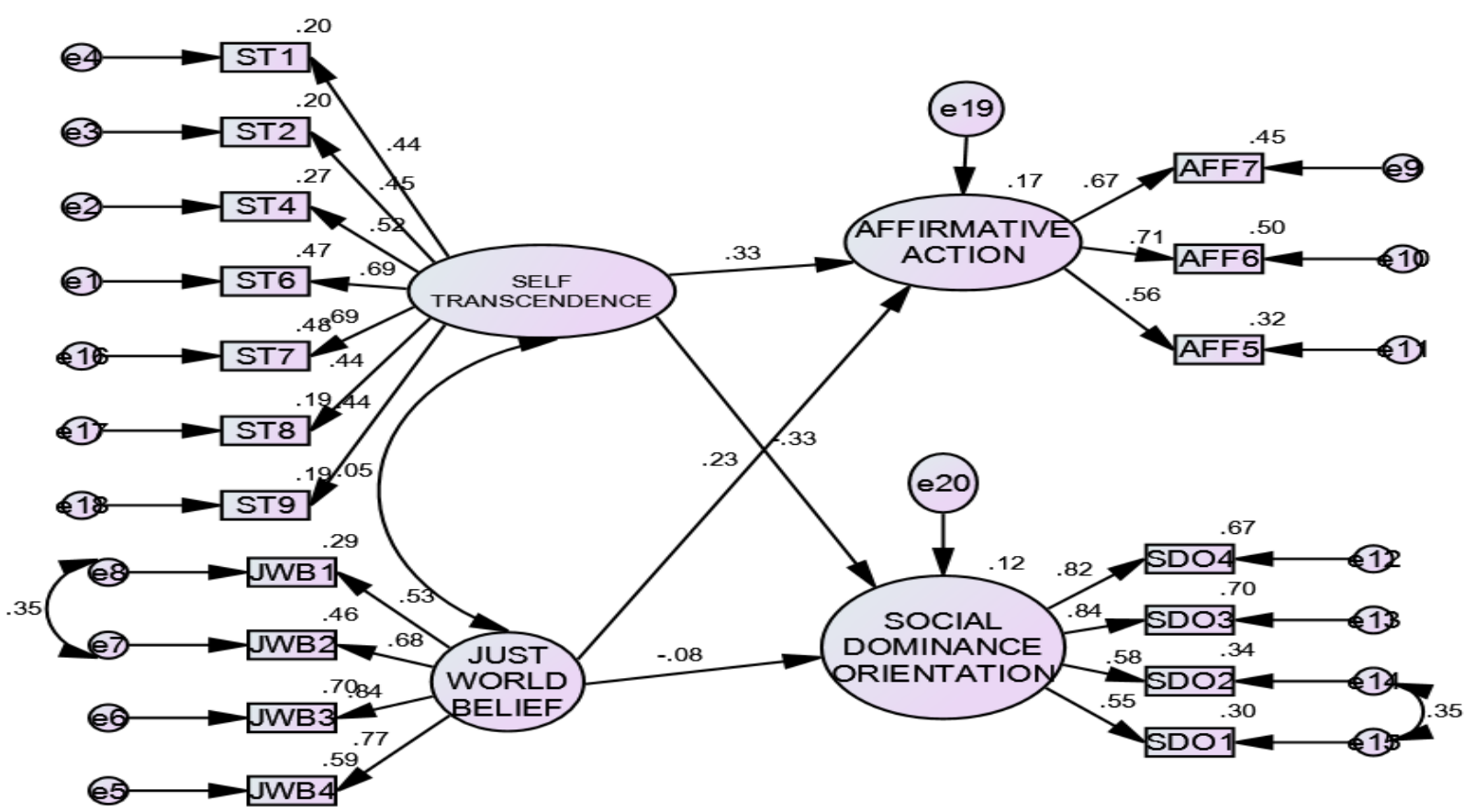


Table 3: Regression Paths from ST and JWB to AFF and SDO

\begin{tabular}{llllll}
\hline iv & dv & $C R$ & $S E$ & $P$ & $\beta$ \\
\hline ST & AFF & 4.11 & .08 & $<.001$ & .33 \\
ST & SDO & -4.60 & .09 & $<.001$ & -.33 \\
JWB & AFF & 3.14 & .06 & .002 & .23 \\
JWB & SDO & -1.28 & .07 & .202 & -.08
\end{tabular}

Note: ST: Self-transcendence. JWB: just-world belief. AFF: affirmative action. SDO: social dominance orientation. Iv: independent variable. $d v$ : dependent variable. CR: critical ratio. SE: standard error.

\section{Discussion}

The authors set out to examine the roles of worldviews in social attitudes. ST and JWB were examined in relation to support for AFF and SDO. Two hypotheses were formulated of which one was fully supported while the other was partly supported. Data analysis revealed that ST predicts more support for AFF and less SDO. This means that ST beliefs are associated with greater other-concern. This relationship might be based on the perception that if other people experience well-being such wellness will transcend the individual to impact others positively. As such transcendent belief is likely to motivate a commitment to being fair to others or doing right by others. This could include supporting actions or policies that aim to improve the welfare of disadvantaged groups. In the same vein, ST embodies feelings of compassion and gratitude for one's life outcomes or situations (Oriol et al., 2020; Stellar et al., 2017). Feelings of gratitude for achievements have been linked to more prosocial behaviours (Alkozei et al., 2018; Piff et al., 2015). Gratitude is said to stem from the perception that one has benefited from other people's efforts (McCullough et al., 2001). Therefore, feeling grateful for what one has and believing personal achievements to be part of a transcendent reality may motivate wanting to support others and disapproving policies or processes that disfavour some groups. The pattern of relationship between ST and support for AFF and SDO is supported by research findings that have linked ST to empathy towards other people and prosocial behaviour (Ardenghi et al., 2021; Łowicki et al., 2020; Pantaléon et al., 2019; Sugiura et al., 2020).

Furthermore, JWB showed a direct relationship with support for AFF. With a belief in a justworld, support for AFF is likely to increase. This finding could be situated within the viewpoint that a belief in a just-world is inclusive of a belief in the principle of reciprocity, such as "what goes around comes around" (FeldmanHall et al., 2018; Hafer, 2000; Lerner, 1980). This suggests that one might commit to favourable acts towards others in expectation of a reward. This is supported by the evolutionary perspective which identifies "probability of reciprocation" as one of the conditions under which altruism evolved (Stevens \& Duque, 2016). As such JWB would also include a belief that "if one does good then one deserves good" or "good things happen to good people and bad things to bad people" (FeldmanHall et al., 2018; Hafer, 2000; Lerner, 1980).

The inclusiveness of the principle of reciprocity in JWB as the mechanism through which JWB is related to other-concern is supported by theoretical and empirical research findings linking other-concern to self-interest or personal gain (FeldmanHall et al., 2018; Melamed et al., 2020; 
Molleman et al., 2013; Simpson et al., 2018). For example, FeldmanHall et al. (2018) assert that reciprocity is the mechanism that motivates compliance with social norms such as fairness, altruism, trust, and cooperation. This pathway to compliance occurs through learning that there are societal devices for rewarding compliance and punishing deviants. Thus, individuals could engage in prosocial acts just to avoid the negative consequences of not doing so. Likewise, Melamed et al. (2020) found that reciprocity influenced the amount an individual gives to others. Specifically, the authors found that when an alter will subsequently be in a position to reciprocate an act of giving, participants gave more. Also, the amount given to an alter was directly associated with the number of others present. This suggests that people might derive satisfaction from being observed when gifting others.

Another plausible explanation for this finding asides from the self-interest hypothesis is that JWB can also be linked to other-concern through the cognitive evaluation that humans are also responsible for creating outcomes for other people (FeldmanHall et al., 2018; Stroebe et al., 2015). This could consequently drive a commitment towards concern or ensuring justice for other people. In addition, encountering the misfortunes of others can motivate a desire to restore justice and improve outcomes for those people (Andre \& Velasquez, 2015; Lerner, 1980).

For the relationship between JWB and SDO, although bivariate analysis shows a significant negative relationship between them, JWB was not a significant predictor of SDO. Nevertheless, this result supports the hypothesised positive link between a JWB and other-concern. In addition, ST and JWB exerted more influence on support for AFF among males than females. This result could be attributed to females being inherently more orientated towards care for others than males. Females have been shown to be more empathic and tolerant because socialisation for females emphasises the ethics or morals of care (Ardenghi et al., 2021; Schwartz \& Rubel, 2005). Lastly, age and gender were not associated with ST, JWB, AFF, and SDO.

\section{Implications of Findings}

The findings of this study suggest that the worldviews which people hold exert influence on their social and political attitudes. The university is comprised of people from all walks of life. This study, therefore, illuminates factors that could be implicated in intolerance and conflict between groups in an educational setting. Hence, findings can assist in the understanding and management of conflicts among students. This would go a long way in creating a conducive learning environment and improving learning outcomes for all students particularly those from disadvantaged groups.

Perception and acceptance of educational policies on AFF for disadvantaged groups by individuals of dominant/ privileged majority group could be dependent on the individual's sensitivity such as their perception of world order and how such prescribes how one ought to behave towards fellow humans. Knowledge of such sensitivities could play an important role in designing strategies to break down resistance to AFF policies.

Furthermore, the university houses students who would eventually preside and govern societal processes including those that concern social inequality and justice for all persons and groups. 
As such attitude change regarding social equity and social injustice could be inculcated in school curriculums to encourage the development of positive attitudes towards fairness and inclusion.

Equity, fairness, and justice are ideals aimed for in every democratic society. Since worldviews are learnt and are reflected in a society's culture, societal level attitude change through revamping worldviews that endorses social inequity/inequality might be a way to ensure social learning of other-concern.

In conclusion, the findings of this study contribute to the literature on worldviews and social attitudes and their possible implications for the acceptance of social policies on social equity, equality, and inclusion.

\section{Limitations of the Study and Directions Future Research}

The participants in this study were undergraduate students drawn from within one university. This affects the generalizability of the findings to the larger population. Nonetheless, participants were drawn from a public university comprised of students from different socioeconomic backgrounds. This, therefore, improves the applicability of findings. Future research should explore other worldviews that could have implications for social and political attitudes. Also, participants should be drawn from different settings to improve the generalisability of findings. Equally, it is important to explore the specific pathways through which worldviews are related to other-concern.

\section{Acknowledgements}

The authors appreciate the Project Supervisees of the 2018/2019 academic session who participated in the data collection for this study.

\section{References}

Aerts, D., Apostel, L., De Moor, B., Hellemans, S., Maex, E., Van Belle, H., \& Van der Veken, J. (2007). Worldviews from fragmentation to integration. https://www.vub.be/CLEA/pub/books/worldviews.pdf

Akhtari, M., Bau, N., \& Laliberté, J. P. (2020). Affirmative action and pre-college human capital. National Bureau of Economic Research Working Paper No. 27779 September 2020 JEL No. 121, 124, J15, J24, J48. http://www.nber.org/papers/w27779

Alkozei, A., Smith, R., \& Killgore, W. D. (2018). Gratitude and subjective wellbeing: a proposal of two causal frameworks. Journal of Happiness Studies, 19, 1519-1542. https://doi.org/10.1007/s10902-017-9870-1

Andre, C. \& Velasquez, M. (2015, November 3). The just world theory. Markkula Center for Applied Ethics. https://www.scu.edu/ethics/ethics-resources/ethical-decisionmaking/the-just-world-theory/

Ardenghi, S., Rampoldi, G., Bani, M. \& \& Strepparava, M. G. (2021). Personal values as early predictors of emotional and cognitive empathy among medical students. Current Psycholology. Advance online publication. https://doi.org/10.1007/s12144-021-01373-8 Ashanti, E. (2008). Social dominance orientation and reactions to affirmative action policies and beneficiaries: A test of the mediating effects of perceptions of race-based inequities and attitudes toward diversity [Doctoral dissertation, Clemson University]. Clemson University, https://tigerprints.clemson.edu/all dissertations/216 
Olonisakin, T. T. et al., Social worldviews and social attitudes: Examining the psychological correlates for other-concern

Bai, J. (2016). Perceived support as a predictor of acculturative stress among international students in the United States. Journal of International Students, 6(1), 93-106.

https://files.eric.ed.gov/fulltext/EJ1083271.pdf

Bandyopadhyay, S. \& Green, E. (2018). Explaining inter-ethnic and inter-religious marriage in Sub-Saharan Africa CGR Working Paper 90. Centre for Globalisation Research School of Business and Management, University of London. http://webspace.qmul.ac.uk/pmartins/CGRWP90.pdf

Barrett, R. (2021). Understanding values, beliefs and worldviews and how they relate to consciousness. Barrett Academy. https://assets.websitefiles.com/5da907821e9c2c81a986dd1e/60539d5ea6c510c9dbf5cc77 Understanding\% 20Values\%2C\%20Beliefs\%20and\%20Worldviews\%20and\%20how\%20they\%20relate\%20 to\%20consciousness.pdf

Bègue, L. \& Charmoillaux, M. \& Cochet, J. \& Cury, C. \& Suremain, F. (2008). Altruistic behavior and the bidimensional just world belief. The American Journal of Psychology, 121(1), 4756. https://doi.org/10.2307/20445443

Bierhoff, H. (2002). Just world, social responsibility, and helping behavior. In M. Ross \& D. Miller (Eds.), The justice motive in everyday life (pp. 189-203). Cambridge University Press. https://doi.org/10.1017/CB09780511499975.011

Bizer, G. Y. \& Hart, J. B. \& Jekogian, A. M. (2012). Belief in a just world and social dominance orientation: evidence for a mediational pathway predicting negative attitudes and discrimination against individuals with mental illness. Personality and Individual Differences 52, 428-432. https://doi.org/10.1016/j.paid.2011.11.002

Buchner, A., Erdfelder, E, Faul, F \& Lang, A. G. (2019). G*Power 3.1.9.4. https://download.cnet.com/G-Power/3000-2054 4-10647044.html

Cangur, S. \& Ercan, I. (2015). Comparison of model fit indices used in structural equation modeling under multivariate normality. Journal of Modern Applied Statistical Methods, 14(1), 152-167. https://doi.org/10.22237/jmasm/1430453580

Caplan, N. A. \& Stevens, S. G. (2017). Step out of the cycle: Needs, challenges, and successes of international undergraduates at a US university. English for Specific Purposes, 46, 1528.

Cheng, Y., Nudelman, G., Otto, K. \& Ma, J. (2020). Belief in a just world and employee voice behavior: The mediating roles of perceived efficacy and risk. The Journal of Psychology, 154(2), 129-143. https://doi.org/10.1080/00223980.2019.1670126

Crosby, F. J., Iyer, A. \& Sincharoen, S. (2006). Understanding affirmative action. Annual Review of Psychology 57, 585-611. https://doi.org/10.1146/annurev.psych.57.102904.190029

De Caroli, M. E. \& Sagone, E. (2014). Belief in a just world, prosocial behavior, and moral disengagement in adolescence. Procedia-Social and Behavioral Sciences, 116, 596-600.

Dhakal, R. (2017). Education and health impacts of an affirmative action policy on minorities in India. [Dissertations, University of South Florida]. http://scholarcommons.usf.edu/etd/7017

Dzansi, D. Y. \& Mogashoa, L. (2013). International students in the classroom: A South African evidence of impact on lecturer and domestic student classroom practices and classroom effectiveness. Journal of Sociology and Social Anthropology, 4(3), 227-237.

https://doi.org/10.1080/09766634.2013.11885600 
FeldmanHall, O., Son, J., \& Heffner, J. (2018). Norms and the flexibility of moral action. Personality Neuroscience, 1: e15, 1-14. https://doi.org/10.1017/pen.2018.13

Flanagan, R. (2020).Worldviews: Overarching concept, discrete body of knowledge or paradigmatic tool?. Journal of Religious Education 68, 331-344. https://doi.org/10.1007/s40839-020-00113-7

Glaser, J. (2005). Intergroup bias and inequity: Legitimizing beliefs and policy attitudes. Social Justice Research, 18(3). https://doi.org/10.1007/s11211-005-6825-1

Hafer, C. L. J. (2000). Do innocent victims threaten the belief in a just world? Evidence from a modified Stroop task. Personality and Social Psychology, 79(2), 165-73. https://doi.org/10.1037//0022-3514.79.2.165

Harding, W. G., McConatha, J. T. \& Kumar, V. K. (2020). The relationship between just world beliefs and life satisfaction. International Journal of Environmental Research and Public Health, 17, 6410. https://doi.org/10.3390/ijerph17176410

Ho, A. K., Sidanius, J., Kteily, N., Sheehy-Skeffington, J, Pratto, F., Henkel, K. E., Foels, R., \& Stewart, A. L. (2017). The nature of social dominance orientation: Theorizing and measuring preferences for intergroup inequality using the new $\mathrm{SDO}_{7}$ scale. Journal of Personality and Social Psychology, 109(6), 1003-1028.

Hu, L. \& Bentler, P. (1999). Cutoff criteria for fit indexes in covariance structure analysis: Conventional criteria versus new alternatives. Structural Equation Modeling, 6(1), 1-55. https://doi.org/10.1080/10705519909540118

Jost, J. T. \& Hunyady, O. (2005). Antecedents and consequences of system-justifying ideologies. Current Directions in Psychological Science, 14(5), 260-265.

Kim, H. (2013). Statistical notes for clinical researchers: assessing normal distribution (2) using skewness and kurtosis. Restorative Dentistry and Endodontics, 38(1), 52-54. http://dx.doi.org/10.5395/rde.2013.38.1.52

Kleppest $\varnothing$, T. H., Czajkowski, N. O., Vassend, O., Røysamb, E., Eftedal, N. H., SheehySkeffington, J., Kunst, J. R., \& Thomsen, L. (2019). Correlations between social dominance orientation and political attitudes reflect common genetic underpinning. Proceedings of the National Academy of Sciences of the United States of America, 116(36), 17741-17746. https://doi.org/10.1073/pnas.1818711116

Kline, R. B. (2005). Principles and practice of structural equation modeling. The Guilford Press.

Kline, R. B. (2011). Principles and practices of structural equation modelling (3rd ed.). The Guilford Press.

Koea, J, Rahiri, J. L., \& Ronald, M. (2021). Affirmative action programmes in postgraduate medical and surgical training- A narrative review. Medical Education, 55, 314- 321. https://doi.org/10.1111/medu.14350

KPMG. (2016). Assessing the impact of Right to Education Act. https://assets.kpmg/content/dam/kpmg/pdf/2016/03/Assessing-the-impact-of-Rightto-Education-Act.pdf

Landström S., Strömwall L. A., \& Alfredsson H. (2015). Blame attributions in sexual crimes: Effects of belief in a just world and victim behavior. Nordic Psycholology, 68, 2-11. https://doi.org/10.1080/19012276.2015.1026921

Lau, W. W. F., Hui, C. H., Lam, J., Lau, E. Y. Y., Ng, D. \& Cheung, S. (2015). Psychometric evaluation of the spiritual transcendence scale in a Chinese sample: Is there factorial 
invariance across gender, occupation, and religion? The International Journal for the Psychology of Religion, 26, 136-51. https://doi.org/10.1080/10508619.2015.1021654 Lerner, M. J. (1980). The belief in a just world: A fundamental delusion. Springer, 9-30. https://doi.org/10.1007/978-1-4899-0448-5 2

Łowicki, P., Zajenkowski, M., \& Cappellen, P. V. (2020). It's the heart that matters: The relationships among cognitive mentalizing ability, emotional empathy, and religiosity. Personality and Individual Differences, 161, 109976.

https://doi.org/10.1016/j.paid.2020.109976

Lucas, T. (2009). Justifying outcomes versus processes: Procedural and distributive justice beliefs as predictors of positive and negative affectivity. Current Psychology, 28(4), 249265. https://doi.org/10.1007/s12144-009-9066-x

Lucas, T., Alexander, S., Firestone, I. J., \& LeBreton, J. M. (2007). Development and initial validation of a procedural and distributive just world measure. Personality and Individual Differences, 43(1), 71-82. https://doi.org/10.1016/j.paid.2006.11.008

Lucas, T., Zhdanova, L. \& Alexander, S. (2011). Procedural and distributive justice beliefs for self and others assessment of a four-factor individual differences model. Journal of Individual Differences, 32(1), 14-25. https://doi.org/10.1027/1614-0001/a000032

Mahsa, M. (2020). Comparison of acculturation and social support among the depressed and nondepressed international students [Master's thesis, Near East University]. http://docs.neu.edu.tr/library/6842089900.pdf

McCullough, M. E., Kilpatrick, S. D., Emmons, R. A., \& Larson, D. B. (2001). Is gratitude a moral affect? Psychological Bulletin, 127(2), 249-266. https://doi.org/10.1037/00332909.127.2.249

Mebane, M. E., Aiello, A., \& Francescato, D. (2020). Political gender gap and social dominance orientation. Politics and Elections, 1-15. https://doi.org/10.5772/intechopen.92222

Melamed, D., Simpson, B., \& Abernathy, J. (2020). The robustness of reciprocity: Experimental evidence that each form of reciprocity is robust to the presence of other forms of reciprocity. Science Advances, 6(23), eaba0504. https://doi.org/10.1126/sciadv.aba0504

Molleman, L., van den Broek, E. \& Egas, M. (2013). Personal experience and reputation interact in human decisions to help reciprocally. Proceedings Biological Sciences, 280(1757), 20123044. https://doi.org/10.1098/rspb.2012.3044

Morgenroth, T. \& Ryan, M. (2018). Quotas and affirmative action: Understanding group-based outcomes and attitudes. Social and Personality Psychology Compass, 3, e12374. https://doi.org/10.1111/spc3.12374

Nilsson, A., \& Jost, J. T. (2020). Rediscovering Tomkins' polarity theory: Humanism, normativism, and the psychological basis of left-right ideological conflict in the U.S. and Sweden. PLoS ONE 15(7), e0236627. https://doi.org/10.1371/journal

Olonisakin, T. T. (2019). Motivated cognitions, xenophobia and ethnocentrism: The moderating roles of cultural intelligence ad group status [Doctoral dissertation, Ekiti State University].

Olonisakin, T. T. \& Adebayo, S. O. (2021). Xenophobia: Scale development and validation. Journal of Contemporary African Studies. Advance online publication. https://doi.org/10.1080/02589001.2020.1853686

Oriol, X., Unanue, J., Miranda, R., Amutio, A. \& Bazán, C. (2020). Self-transcendent aspirations and life satisfaction: The moderated mediation role of gratitude considering conditional 
Olonisakin, T. T. et al., Social worldviews and social attitudes:

Examining the psychological correlates for other-concern

effects of affective and cognitive empathy. Frontiers in Psychology, 11, 2105.

https://doi.org/10.3389/fpsyg.2020.02105

Pantaléon, N., Chataigné, C., Bonardi, C. \& Long, T. (2019). Human values priorities: Effects of self-centredness and age. Journal of Beliefs \& Values, 40(2), 172-186.

https://doi.org/10.1080/13617672.2018.1554880

Piedmont, R. L. (1999). Does Spirituality Represent the Sixth Factor of Personality? Spiritual Transcendence and the Five-Factor Model. Journal of Personality, 67(6), 985-1013. https:// doi.org/10.1111/1467-6494.00080

Piedmont, R. L. (2010). Assessment of spirituality and religious sentiments, technical manual (2nd ed.). Timonium.

Piedmont, R. L. (2012). Overview and development of measure of numinous constructs: The assessment of spirituality and religious sentiments (ASPIRES) scale. In L. J. Miller (Ed.), The Oxford handbook of psychology and spirituality (pp. 104-122). Oxford University Press.

Piff, P. K., Dietze, P., Feinberg, M., Stancato, D. M., \& Keltner, D. (2015). Sublime sociality: How awe promotes prosocial behavior through the small self. Journal of Personality and Social Psychology, 108(6), 883-899. http://dx.doi.org/10.1037/pspi0000018

Piotrowski, J. P., Żemojtel-Piotrowska, M. A., Piedmont, R., Baran, T., \& Skrzypińska, K. (2019). The assessment of spirituality and religious sentiments (ASPIRES) scale: Examining a spiritual transcendence nomological net in Polish context. Psychology of Religion and Spirituality, 13(1), 36-45. https://doi.org/10.1037/rel0000273

Pratto, F., Sidanius, J. \& Levin, S. (2006). Social dominance theory and the dynamics of intergroup relations: Taking stock and looking forward. European Review of Social Psychology, 17, 271-320. https://doi.org/10.1080/10463280601055772

Pratto, F., Sidanius, J., Stallworth, L. M. \& Malle, B. F. (1994). Social dominance orientation: A personality variable predicting social and political attitudes. Journal of Personality and Social Psychology, 67(4), 741-763. https://doi.org/10.1037/0022-3514.67.4.741

Ratshilaya, A. J. (2017). Exploring the social and academic experiences of international students in South African Universities.

https://repository.up.ac.za/bitstream/handle/2263/67887/Ratshilaya Exploring 2017.p $\mathrm{df}$ ? sequence $=1 \&$ isAllowed $=\mathrm{y}$

Scacco, A. \& Warren, S. S. (2018). Can social contact reduce prejudice and discrimination? Evidence from a field experiment in Nigeria. American Political Science Review, 112(3), 654-677. https://doi.org/10.1017/S0003055418000151

Schwartz, S. H., \& Rubel, T. (2005). Sex differences in value priorities: Cross-cultural and multimethod studies. Journal of Personality and Social Psychology, 89(6), 1010-1028. https://doi.org/10.1037/0022-3514.89.6.1010

Simkin, H., \& Piedmont, R. L. (2018). Adaptation and validation of the assessment of spirituality and religious sentiments (ASPIRES) scale short form into Spanish. Revista Latinoamericana de Psicología Positiva, 4, 97-107. https://www.academia.edu/40357553/Adaptation and Validation of the Assessment of Spirituality and Religious Sentiments ASPIRES scale short form into spanish

Simpson, B., Harrell, A., Melamed, D., Heiserman, N., Negraia, D. V. (2018). The roots of reciprocity: Gratitude and reputation in generalized exchange systems. American Sociological Review, 83(1), 88-110. https://doi.org/10.1177/0003122417747290 
Stellar, J. E., Gordon, A. M., Piff, P. K., Cordaro, D., Anderson, C. L., Bai, Y., Maruskin, L. A. \& Keltner, D. (2017). Self-transcendent emotions and their social functions: Compassion, gratitude, and awe bind us to others through prosociality. Emotion Review, 9(3), 200207. https://doi.org/10.1177/1754073916684557

Stevens, J. R. \& Duque, J. F. (2016). Psychology of reciprocal altruism. In T. K. Shackelford \& V. A. Weekes-Shackelford (Eds.), Encyclopedia of evolutionary psychological science. Springer. https://doi.org/10.1007/978-3-319-16999-6 3051-1

Stroebe, K., Postmes, T., Täuber, S., Stegeman, A., \& John, M. (2015). Belief in a just what? Demystifying just world beliefs by distinguishing sources of justice. PLoS One, 10(3), e0120145. https://doi.org/10.1371/journal.pone.0120145

Sugiura, M., Nouchi, R., Honda, A., Sato, S., Abe, T., \& Imamura, F. (2020). Survival-oriented personality factors are associated with various types of social support in an emergency disaster situation. PLoS One 15(2), e0228875. https://doi.org/10.1371/journal.pone.0228875

Tabachnick, B. G., \& Fidell, L. S. (1996). Using multivariate statistics (3rd ed.). HarperCollins. Verkuyten, M, Yogeeswaran, K, Adelman, L. (2019). Toleration and prejudice-reduction: Two ways of improving intergroup relations. European Journal of Social Psychology, 50, 239- 255. https://doi.org/10.1002/ejsp.2624

Wakslak, C., Jost, J. T., Tyler, T. R., \& Chen, E. (2007). Moral outrage mediates the dampening effect of system justification on support for redistributive social policies. Psychological Science, 18(3), 267-274. https://doi.org/10.1111/j.1467-9280.2007.01887.x

Werner, M. (2003). Identification of multivariate outliers in large data sets [Doctoral dissertation, University of Colorado ]. http://math.ucdenver.edu/graduate/thesis/werner thesis.pdf

Yaden, D. B., Haidt, J., Hood, R. W., Vago, D. R., \& Newberg, A. B. (2017). The varieties of selftranscendent experience. Review of General Psychology, 21(2), 143-160. https://doi.org/10.1037/gpr0000102 